\title{
High Temperature and Pressure reactive flows through porous media.
}

\author{
N Gascoin* \\ PRISME, IUT Bourges, 63, avenue de Lattre de Tassigny - 18000 Bourges, France
}

\begin{abstract}
Large heat load are encountered in hypersonic and space flight applications due to the high vehicle speed (over Mach 5, i.e. $5000 \mathrm{~km} . \mathrm{h}^{-1}$ ) and to the combustion heat release. If passive and ablative protections are a way to ensure the thermal management, the active cooling is probably the most efficient way to enable the structures withstanding of such large heat load. In some conditions, transpiration cooling will be used. In this paper, the permeation of fuels and other fluids through porous media is studied up to $1150 \mathrm{~K}$ and 60 bars. A dedicated experimental bench has been established to ensure the monitoring of temperature, pressure, mass flow rate and chemical composition (Gas Chromatograph, Mass Spectrometer, Infra-Red spectrometer) in stationary and transient conditions. The tests on metallic and composite samples have been conducted with $\mathrm{N}_{2}, \mathrm{CH}_{4}, \mathrm{H}_{2}+\mathrm{CH}_{4}$ mixtures and synthetic fuels $\left(n-\mathrm{C}_{12} \mathrm{H}_{26}\right)$. The pressure losses comparison with the mass flow rate has enabled the determination depending on the temperature of the Darcian permeability, $K_{D}$ the linear contribution, and of the Forchheimer's term, $K_{F}$ the quadratic one. The fuel pyrolysis in such low Reynolds flow has been investigated. The blockage effect due to coking activity has been estimated.
\end{abstract}

Keywords: Permeation; CMC composites; Darcy; Forchheimer; Pyrolysis; Supercritical state.

\section{Introduction}

For high-speed applications, the material withstanding and the cooling management are the key issues which limit the flight Mach number to about 3 (Steelant 2008; Bouchez 2008; Steelant 2009). The hypersonic flight can be achieved in the future only if a strong development of light-weight and high-temperature composite materials are proposed. The materials and cooling techniques and their interaction with aero-thermal loads must be addressed (Gascoin 2008a). The European ATLLAS project (Aerodynamic and Thermal Load interactions with Lightweight Advanced materials for high Speed) of the European Space Agency is notably investigating this topic. Among the materials which are intended to be used for high-speed flight are the metallic and mostly the composite ones. The porosity of Ceramic Matrix Composite (CMC), used as high temperature material for combustion chamber or stagnation regions of hypersonic vehicles, allows the combination with transpiration cooling. Despite there are some results associated to these points, the scientific community still face a big lack in the correct evaluation of porous flow behaviour with conjugate heat transfer. This is of concern for rocket engine in near future (Riccius 2005).

\subsection{Permeation phenomenon}

Studying the permeation process is of primary importance and some studies can be found in relationship with this need, experimentally (Langener 2008, Tully 2005) or numerically (Riccius 2005, Murthy 2000); even mathematically (Kim 1999). Such studies are not only dedicated to the flow description but also to the heat transfers (Kim 1999, Krishna 2008, Rajagopal 2009, Zhang 1999, Hadim 1994); for example for configurations close to fuel cooled structures (Zhao 2003) and also for geophysics applications (Hadim 1994). The flows in porous media are widely studied under common operating conditions.

The permeation mainly depends on the material structure which can be considered at different scales. The permeability is said to be global when considering the global structure at a macroscale (i.e. all the material's components are considered). To the opposite, microscale deals with the component of the matrix and the

\footnotetext{
* Corresponding author. Tel.: +33 248238 473; Fax: +33 248238471.

E-mail address: Nicolas.Gascoin@bourges.univ-orleans.fr (N. Gascoin).
} 
permeability measured at this level gives information about the flow comportment (Zhou 2006). Between those two levels, some authors introduce the notion of mesoscale where the matrix is considered as a porous continuum. At this scale, the fluid filtrates through the porous matrix according to Darcy's law. For each scale, the permeability depends on several elements: the material employed (composite, metal, ceramic...), the structure morphology (tubular, plate...), the layer number (simple or multilayer composite), the layer disposition (angle between each layer, i.e. 0,45 or $90^{\circ}$ ), the presence of cracks (their orientation, the connexion between them) (Soller 2009, Park 2003, Federico 2008, Xu 2008, Shields 2008, Gascoin 2008b, Peddiraju 2005, Kladias, Choi 1998), the aging and the damage (outer and inner cracking, delamination) (Park 2003). At the macroscale, the manufacturing process has a huge effect on the material permeability.

The problem is even trickier (Gascoin 2008b) when the coolant can react with the material or within the material (local coking). The use of metallic structure is generally a more feasible way because the porosity is controlled and can be more easily studied because it does not depend on the complex production process itself, contrary to what it is for composite structures. A lot of studies, often under high pressure (up to 20 bars) are available for ambient conditions or average temperature conditions (under 800 K) (Langener 2008, Park 2003, Peddiraju 2005). But only few are dedicated to both high temperature and high pressure conditions. Furthermore, they focus on the filtration of "inert" gases (even oxidative ones like the air or non reacting ones like hydrogen) (Langener 2008, Park 2003, Peddiraju 2005). Very few are studying the chemical reaction through the porous media. These reactions of pyrolysis are due to the decomposition of heavy molecules in smaller ones due to the temperature. The residence time of the fluid through the porous media has a major impact on the chemical process; the pressure appears as a third parameter after temperature and time (Gascoin 2008a). In lab conditions, knowing the mass flow rate and the pressure can give the permeability. For aerospace applications, the residence time of the fluid can be predicted inside the porous media as a function of temperature thanks to the permeability. This is useful to predict the pyrolysis phenomenon of the fuel through the composite structure, thus the pyrolysis and associated coke formation, which modify the permeability and thus the cooling efficiency.

In case of chemical reaction, the formation of carbon deposit (Gascoin 2008b) on the surface of the composite but also inside the porosities can impact the permeability. These reactions can be due to the thermal fluid decomposition and to the degradation of the composite itself. The permeability can thus vary by modification of the porous material itself during the degradation (Kladias). Furthermore, a catalytic effect can appear depending on the nature of the porous media.

\subsection{Analytical formulations}

To the author's knowledge, most of analytical formulas aiming at describing the through flow in porous media are given in stationary condition. No transient behaviour is described with simplified equation, except if NavierStokes equations are considered in case of Computational Fluid Dynamics code. For a large range of flow regimes, the Brinkman's equation is used to describe the macroscopic fluid flow (Eq. 1). The pressure drop through the porous media (left term) is linearly proportional to the velocity for low flow rates (Darcian flows) and to its square at higher flow rates (non-Darcian flows). The right term of the Eq. 1 is composed of two parts, one related to the Darcy's law for low velocity regime filtration (first right term) and the other quadratic one related to the Stokes's law to ensure the continuity of velocity and stress at the solid-fluid frontier (second right term) (Steelant 2009). The gravity term is neglected in numerous studies (but not all, for example in case of vertical flows (Zhao 2003)). The Stokes equation is also found as the Forchheimer's equation and it accounts for inertial effects related to the flow resistance (turbulent flows) (Tully 2005, Murthy 2000). Numerous other formulations of the Brinkman's equation are found (Kim 1999, Choi 1998, Martin 2008, Valdes 2007) but they are based on coefficient that still need to be expressed and which physical meaning is not evident. Power laws (Rathish 2003) and cubic laws can be found to describe a large range of flow regimes through porous media (Aulisa 2009, Nguyen 2007, Pazos 2009). The power law can be found under the name of Izbash law (Moutsopoulos 2009). The fundamentals of the Brinkman's equation can be found in Valdes paper (2007) for more details.

$$
\frac{\Delta P}{L}=\mu \cdot \frac{V}{\mathrm{~K}_{D}}+\rho \cdot \frac{V^{2}}{\mathrm{~K}_{F}}
$$

with $L$ the external mean sample thickness, $\mu$ the dynamic viscosity at the mean temperature (normally

isothermal), $\rho$ the inlet density (with respect to inlet pressure), $V$ the inlet fluid velocity (with respect to 
macroscopic flow cross-section), $\Delta P=\left(P_{\text {inlet }}^{2}-P_{\text {outlet }}^{2}\right) /\left(2 . P_{\text {inlet }}\right)$ the pressure drop through the porous medium, $K_{D}$ and $K_{F}$ the Darcy's and Forchheimer's terms.

The flow regime related to the Forchheimer's term is mostly encountered in fuel cooled structures but also on the degrading thermal protections, whose pyrolysis gases flow through the damaged surface (Martin 2008). Some studies tried to find an analytical expression of the Forchheimer's coefficient but this remains quite a challenging task despite it is of prior importance for flows modelling under high velocity regime. The expressions are generally based on the sphere diameter (if applicable) and on the porosity notably (Tully 2005, Samper 2008). But the discrepancies between resulting numerical flow simulations and experimental data can be large. They generally increase when the ratio of solid-to-fluid thermal conductivity is high (Zhao 2003). This is linked to the fluid expansion through the porous sample, which can not be well simulated without appropriate permeation model. This is reinforced by the non uniform temperature caused by the characteristic time of heat transfer, which is much higher than the residence time of the fluid in the porous media.

Thus, experimental estimation is probably the most appropriate way to estimate such parameter due to its heavy dependence on fabrication process of the porous media notably. The norm ISO 4022 (1987 with update in 2006) proposes a method to determine the permeability of porous samples. The Brinkmann's equation (Eq. 1) is rewritten (Eq. 2) by dividing it by $\mu . V$. Thus, the term $\frac{\Delta P}{L . \mu . V}$ is plotted as a function of $\frac{\rho . V}{\mu}$. The origin is linked to the Darcian term while the angle of climb is related to the Forchheimer's term.

$$
\frac{\Delta P}{L . \mu . V}=\frac{1}{K_{D}}+\frac{\rho . V}{\mu . K_{F}}
$$

with $L$ the external mean sample thickness, $\mu$ the dynamic viscosity at the mean temperature (normally isothermal), $\rho$ the mean density (with respect to mean pressure between upstream and downstream), $V$ the mean fluid velocity (with respect to macroscopic flow cross-section), $\Delta P=P_{\text {inlet }}-P_{\text {outlet }}$ the pressure drop through the porous medium, $K_{D}$ and $K_{F}$ the Darcy's and Forchheimer's terms. In this paper, the cross-section value is based on $16 \mathrm{~mm}$ diameter.

The frontier between the two flow conditions (Darcy and Forchheimer) is unclear. Generally, the Reynolds number based on pore length or diameter is considered (Martin 2008) but this is difficult because the porosity is not obvious in CMC structures. Furthermore, the flow regime can vary depending on the cracks formation (Xu 2008), on their width and on their spacing notably. A Darcy flow can turn into non-Darcy flow if fissures appear (Choi 1998) and two porosity (damaged and non damaged material) can be considered to represent the though flow thanks to Brinkman's equation with Forchheimer's term (Choi 1998). Other formulas and methods can be used for determining $K_{D}$ and $K_{F}$. They will be investigated in the time to come.

\subsection{Multiphysics considerations}

The filtration section of the porous sample is often used in the Stokes' equation. Nevertheless, the section occupied by the gas in a cross section of the gas-filled sample in the direction of the flow should be considered (Park 2003). Furthermore, the dynamic viscosity, which appears in the Brinkman's equation, is often considered to be the one of the fluid. It remains constant in most of experimental and numerical works. Nevertheless, this is questionable because this parameter varies across the porous media in case of reactive flow or non uniform temperature system. The viscosity term in the Stokes's equation (first right term in Eq. 1) should be modified as follows: $\nabla(\mu \nabla V)$ (Aulisa 2009). Mathematical considerations can be found on this point to justify using a modified viscosity (Hansbo 2009).

Other phenomena are related to permeation. The thermophoresis (laminar flow induced by thermal gradient) can be related to the flow through porous media in case of heating (Seddeek 2006) but this phenomenon is very difficult to consider experimentally due to measurement issue. Multiphase flow through porous media would be also of great interest but very few studies are dedicated to this point due to experimental difficulties (Seddeek 2006). Very specific applications on CMC porous material can be also found, such as the shock wave propagation through porous sample (Seddeek 2006). Transient studies (thermal, hydraulic or even chemical gradients) would be of high interest also but due to the large time lag between the increase of system temperature and the one of the sample or of the fluid inside the test bench, it is difficult to conduct such studies. Complex 2-D or 3-D thermal gradients inside 
the porous media cannot be considered experimentally but they may be approached numerically by CFD tools. The few transient studies of the heat transfer in through flow show that the stabilisation time to get a steady-state conditions increases with the porous media thickness (Alkam 1998). If most of the studies are achieved under steady-state conditions, very few papers are available for transient permeation (Kladias, Samper 2008).

Finally, only rare studies focus on the filtration process involving chemical reactions of fuel pyrolysis in composite material. Klimenko and Abdel-Jawad (2007) consider two reactions with four species thanks to numerical simulation. They model the diffusion of species through the porous material depending on the porosity and they do not mention explicitly the Darcy's or Forchheimer's terms. No heat transfer is considered. Other experimental studies are available for inert multi-species flow with diffusion consideration (Polehn). The multi-species flows are of great interest to study the filtration of species, which differs depending on their nature. For pyrolysing fuel for example (in case of fuel cooled structure), the hydrogen and other hydrocarbons formations will be impacted by the filtration process.

In this study, we aim at developing an experimental bench and understanding the fuel permeation and its coupling with chemistry in case of heat load. We present the main results obtained on metallic and composite porous structures with inert and reactive fuels, even under supercritical state.

\section{The experimental bench and specific set-up}

A high pressure and high temperature experimental bench has been set up to enable the study of inert and reactive flows through porous structures (Figure 1). The bench (derived from the one of the COMPARER project

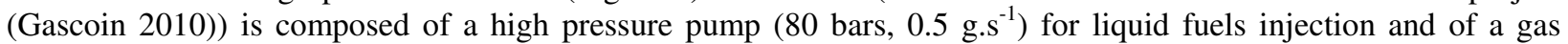
injection for tests with $\mathrm{N}_{2}$ for example. The fluid is heated by a $6 \mathrm{~kW}$ oven (maximum temperature of $1900 \mathrm{~K}$ ). The reactor is mainly composed of a dedicated permeation cell in which the porous media is inserted (to be described later in Figure 2). Numerous sensors (temperature, pressure, mass flow rate) are connected to a data acquisition system (about $1 \mathrm{~Hz}, 16$ bits, 48 channels) to obtain the transient variations of these parameters. The pressure transducers give absolute pressure and two Coriolis mass flow meters are available (upstream and downstream). Three other flow meters are available to measure the mass transfer in the bench to check the mass balance during the test. At least two temperatures are acquired inside the test cell on each faces of the porous sample. The tests are generally conducted under stationary conditions but transient phases can be investigated. When pyrolysis is encountered, after expanding the fluid to atmospheric pressure and cooling it down to ambient temperature, the liquid and gas phases are sampled to be analysed by Gas Chromatograph and Mass spectrometer (GC/MS). A Fourier Transform Infra Red (FTIR) spectrometer NICOLET 6700 is available with a specific and innovative identification and quantification method of pyrolysis products under stationary and transient conditions to enable "real-time" and in-line measures (Abraham 2009).

\section{Figure 1 should be placed here}

The specific cell to be inserted in the furnace is composed of two main parts (High Pressure Chamber -HPC- for the inlet and Low Pressure Chamber -LPC- for the outlet) in order to maintain the porous media in the fluid flow and to avoid leakage (Figure 2a). Despite its small size (external diameter of $40 \mathrm{~mm}$ ), it enables measuring the temperature, pressure and mass flow rate on each side of the porous sample (Figure $2 \mathrm{~b}$ ). The temperature is even measured inside the media to get its spatial longitudinal distribution. Furthermore, fluid sampling is possible before, inside and after the media in order to monitor the pyrolysis activity of the flow.

\section{Figure 2 should be placed here}

The tightness seal of the permeation cell, and particularly with the porous sample, has been verified with nitrogen up to 60 bars. The overall leakage rate under open configuration is lower than $1 \mathrm{ml}^{-\mathrm{min}^{-1}}$ while the minimum process gas flow rate which is considered for this permeation study is $1500 \mathrm{ml}^{\mathrm{min}}{ }^{-1}$. For closed configuration (no flow), the pressure loss is lower than 1 mbar.s ${ }^{-1}$. The pressure drop through the test cell alone is measured according to the mass flow rate to correct the pressure acquisition during the permeation tests through porous sample. Numerous tests have been conducted to define the right experimental protocol and the test cell design notably (three successive ones). About hundred experiments have been performed to be able conducting permeation study in perfectly controlled conditions under operating temperature (1150 K at the porous sample surface) and pressure (60bars), which are rarely reached in such study. The section 3.4 on pyrolysis through porous structure is the achievement of this work, even if larger quantity of experiments is still required to deeply investigate the coupling of permeation with thermal decomposition. The following test conditions and most of the possible combinations have been achieved:

- Fluid phase: liquid, gas, supercritical state

- Fluid nature: n-dodecane, water, methane, natural gas, hydrogen, air, nitrogen 
- Fluid behaviour: inert and reactive (pyrolysis)

- Chemical composition: one species to one hundred of species

- Temperature set-up: from $300 \mathrm{~K}$ to $\mathbf{1 2 0 0} \mathbf{K}$ by step of $100 \mathrm{~K}$

- Absolute Pressure: from 0.5 bar (depressurized system) to 60 bars

- Porous samples: metallic (Stainless Steel, Bronze) and composite (C/SiC CMC) with Darcian permeability from $10^{-17} \mathrm{~m}^{2}$ to $10^{-10} \mathrm{~m}^{2}$.

- Permeation test cell in which the porous sample is located: three design, two material nature (brass and stainless steel)

- Experimental protocol: pressure increase or decrease (flow rate measure), mass flow rate increase or decrease (pressure measure)

\section{Results and discussion}

Due to the implication of density and dynamic viscosity in the pressure drop formula (Eq. 1), their estimation is of great importance because a factor 2 on the viscosity determination is found directly on the Darcian term one. The density is computed on the basis of pressure and temperature measures thanks to the modified perfect gases law with the compressibility factor $\mathrm{Z}$ which depends notably on the critical coordinates and on the Pitzer acentric factor (see Gascoin 2010 for more details). The mean pressure between HPC and LPC is used. The dynamic viscosity is computed thanks to the method proposed by Chung (Poling) and it depends on the temperature and pressure. The experimental data are thus exploited by considering the density and viscosity variations as a function of operating conditions. The chemical composition in case of multi-species flow is considered by mean of mixture law as detailed in Gascoin paper (2010).

\subsection{Characterisation of porous media under ambient temperature}

Six types of metallic porous samples and four types of composite samples have been considered (Figure 3). They are noted SS for Stainless Steel and BR for Bronze (the number indicates the porosity class, SS3 for the SS class 3 Poral for example). SA, SB, SC and SW correspond to composite samples (Bouchez 2002). For each kind of sample, several pieces are available and numbered, for example SC1 to SC8 for the eight available SC samples.

\section{Figure 3 should be placed here}

SEM visualisations have been done on the samples (Figure 4). The SS Poral samples are made of agglomerated particles, theoretically spherical but not here obviously (Figure 4a), while the red brass Poral samples are composed of spheres with mean diameter of $300 \mu \mathrm{m}$ for the class 30 sample (Figure 4b). The sample SA appears visibly to have lower surface porosity (Figure $4 \mathrm{c}, \mathrm{d}$ ). The metallic samples present the huge advantage to be homogeneous, well characterised and extensively studied due to their common and standard configuration while the composite samples highly depends on their fabrication process and they are heterogeneous by nature. A wider characterisation has been conducted on metallic samples and is thus presented despite the composite are the samples of interest for this study. The metallic media are considered for a validation purpose and to propose a reference work.

The Poral ${ }^{\circledR}$ metallic samples come from Federal Mogul (stainless steel and red brass) and several classes of porosity are considered with different thickness (Table 1). The $\mathrm{C} / \mathrm{SiC}$ composite media come from composite panels and the sample types 7 and 8 were used and "damaged" previously under different hot test conditions.

The overall porosity has been determined for each material nature by considering the apparent volume of the samples, their weight and the density of base material (Table 1). It increases with the class of Poral and for the same class, the bronze samples present a higher porosity. Such large porosities should be open (Eudier) and it has been verified experimentally, when possible, by weighting the samples before and after total impregnation of liquid in the porous media. For example, the open porosity of the sample BR30 is estimated around $33.7 \%$, which is lower than the overall porosity values. This is close to the theoretical value of perfect face-centred cubic structure (36\%). It can be concluded that most of the porosity is open. An image processing method has also been applied on SEM observations to estimate the surface porosity after conversion of grey level pictures in black and white images thanks to contour detection. The results are not satisfactory. The overall porosity of CMC is difficult to estimate due to the uncertainty on the density of the initial material and the open porosity also due to low water retention.

The pore diameter $\left(d_{P}=4 \varepsilon /\left(a_{g}(1-\varepsilon)\right)\right.$ with $a_{g}=6 / d_{g}$ the grain area, $\varepsilon$ the overall porosity) is given for all the porous samples in Table 1 . It is based on the grain diameter $\left(d_{g}\right)$, which is measured by SEM images for metallic samples and deduced from Eq. 3 by knowing the Darcy's term for composite samples. It is required to determine the microscale Reynolds number, for which a value close to unity corresponds to the theoretical limit between laminar and turbulent flow, that is to say between Darcy's and Forchheimer's contribution. The pore 
diameter is one to two orders lower for CMC than for metallic samples. The Darcian term can also be estimated by rewriting the Eq. 3 if the grain diameter is measured by SEM ( $h_{K}$ is a constant equal to 4.16) (Dhaouadi 2010). Consequently, this Eq. 3 can be used in two ways depending on the nature of the sample, through the nature of the data which are already known. For BR30 sample, the Darcy's value ranges from $1.08 .10^{-11} \mathrm{~m}^{2}$ to $1.90 .10^{-10} \mathrm{~m}^{2}$ for porosity from $11.8 \%$ to $36 \%$ as estimated above $\left(d_{g}=300 \mu \mathrm{m}\right.$ in conformity with Figure $\left.4 \mathrm{~b}\right)$. This is in good agreement with experimental and reference data $\left(3.33 .10^{-11} \mathrm{~m}^{2}\right.$ to $\left.5.88 .10^{-11} \mathrm{~m}^{2}\right)$. Unfortunately, this approach is not directly applicable to CMC samples because it is very difficult to estimate a grain diameter by SEM images, otherwise it would be possible to give the Darcian value directly for such complex material. As a consequence, the experiments are the most feasible way to determine such permeability data.

$$
d_{g}=\left(36 . h_{K} \cdot K_{D}\right)^{0.5} \frac{(1-\varepsilon)}{\varepsilon}
$$

\section{Figure 4 should be placed here Table 1 should be placed here}

\subsection{Permeation of inert gas at ambient temperature}

Experiments with methane, hydrogen and nitrogen have been conducted but those with inert fluid only are presented in this study. The pressure drop (after correction by those of the test cell alone) and the mass flow rate of nitrogen have been acquired under inert gas flow (Figure 5a) and then the ISO 4022 norm was used to determine both permeability (as exemplified by class 3 sample on Figure 5b). The linear $K_{D}$ and quadratic $K_{F}$ terms of permeation (respectively the origin ordinate and the director coefficient of the linear regression on Figure 5b) are obtained in this section for all the samples (Figure 6). The experimental results on $K_{D}$ are of good agreement with the reference data except for permeability over $10^{-12} \mathrm{~m}^{2}$. This is due to the influence of the cell which "equivalent" permeability (if considering an equivalent $3 \mathrm{~mm}$ thickness) is about $2.10^{-12} \mathrm{~m}^{2}$. Consequently, only the samples with lower permeability can be studied (to limit the noise in comparison to the measured signal). The uncertainty increases with the permeability. No validation data are available for the composite samples. Two different values are found for the samples SC because of their heterogeneity due to damage before the test and manufacturing process. The first value corresponds to four samples (SC1 to SC4) and the second one also (SC5 to SC8). The samples SW may sometimes present sudden pressure release during the test due to a possible seal problem linked to compression of the sample. After measuring the sample thickness, a small but regular decrease of the thickness is seen during five successive tests (from $7.523 \mathrm{~mm}$ to $7.515 \mathrm{~mm}$ ). Large uncertainties may be found for $K_{F}$, notably with CMC samples due to the very high pressure drop encountered even for low mass flow rate (no turbulent regime is clearly observed). The Forchheimer's determination is one order higher for metallic samples than for constructor's data due to the high porosity of concerned samples. The one of low permeability media is supposed to be better.

\section{Figure 5 should be placed here}

The experimental values of this study (Figure 6) are in good agreement with the values generally found for such materials. The permeability ranges generally from $10^{-17} \mathrm{~m}^{2}$ to $10^{-21} \mathrm{~m}^{2}$ for the Darcian term (Park 2003) for non cooled composite structures but it can increase up to $10^{-9} \mathrm{~m}^{2}$ for cooled systems (Tully 2005). When Brinkman's equation is considered (turbulent flow), the Darcy's term for $\mathrm{C} / \mathrm{C}$ porous structure is found to range from $2.10^{-13} \mathrm{~m}^{2}$ to $7.10^{-12} \mathrm{~m}^{2}$ and the Forchheimer's coefficient ranges from $2.10^{-8} \mathrm{~m}$ to $3.10^{-7} \mathrm{~m}$ (langener 2008).

The reproducibility has been tested for all the samples and the Darcy's term varies more for the metallic samples but this is due to the higher permeability (Figure 7). The heterogeneity of the CMC samples due to their fabrication and initial damage of the skin in which they were cut, particularly for samples SC, is also visible.

\section{Figure 6 should be placed here}

Figure 7 should be placed here

The pore Reynolds number has been computed for metallic samples by using the pore diameter determined above. The resulting pressure loss curves of Darcy's and Forchheimer's contribution is given as a function of this Reynolds number (Figure 8). The Darcy's pressure term reaches its limit around unity as proposed by the theory of permeation in porous materials.

\section{Figure 8 should be placed here}

Finally, the permeation through two successive porous samples has been tested with metallic samples at ambient conditions. The hydraulic resistance of samples $R=L / K_{D}$ can be summed to represent analytically the pressure losses of binary sample. 


\subsection{Permeation of nitrogen under high temperature conditions}

Some of the preceding porous media (SS3, SS5, SS40, SA) have been tested under high temperature conditions, with the same test bench and experimental protocol. For the sample SS3 (inserted in a brass permeation cell), the temperature furnace is increased from ambient to $800^{\circ} \mathrm{C}$ by step of $100^{\circ} \mathrm{C}$. Further thermocouples are used inside the furnace to get a better description of the temperature profile. To avoid a large temperature decrease due to the fluid flow, it has been decided to stop the fluid flow between each mass flow rate increase during a time of 1 min to reach approximately the temperature before the preceding flow rate step Five mass flow rates $\left(0.1 \mathrm{~g} . \mathrm{s}^{-1}, 0.2 \mathrm{~g} . \mathrm{s}^{-1}, 0.3 \mathrm{~g} . \mathrm{s}^{-1}\right.$, $0.45 \mathrm{~g} . \mathrm{s}^{-1}, 1 \mathrm{~g} . \mathrm{s}^{-1}$ ) are considered during $20 \mathrm{~s}$ each of them. The temperature in the HPC (High Pressure Chamber) and LPC (Low Pressure Chamber) remains constant in a range of $20 \mathrm{~K}$ for each hydraulic step. For a given thermal step, the LPC temperature remains generally lower than the HPC one, which shows that the fluid is cooled down though the porous sample except for the higher mass flow rate for which the LPC temperature decreases more slowly than the HPC one. This will be of great interest with reactive fluids permeation. The data obtained at $850 \mathrm{~K}$ are judged to be not representative of the permeation due to the major leakage.

The mean sample temperature between the HPC and LPC measured during the test is judged to be "constant" for successive mass flow rate increase (Figure 9). Under these quasi isothermal conditions, the permeation data are given depending on the sample temperature (Figure 10a). Both parameters appear to be mostly constant despite a slight increase of the darcian term around $800 \mathrm{~K}$ and some fluctuations of the Forchheimer's term. The large fluctuation of Forchheimer's term around $585 \mathrm{~K}$ is attributed to measurement error. The data remain in the constructor range (Figure 10b). After the hot test, the same porous sample has been tested at ambient temperature $\left(K_{D}=2.32 .10^{-13} \mathrm{~m}^{2}, K_{F}=3.76 .10^{-7} \mathrm{~m}\right)$. Both tests provide similar results (10\% of discrepancy on the Darcy's term and $19 \%$ on the Forchheimer's one).

\section{Figure 9 should be placed here \\ Figure 10 should be placed here}

Due to limited mass flow rate considered for this test (maximum $1 \mathrm{~g} . \mathrm{s}^{-1}$ ), the Forchheimer's term remains weak compared to the Darcian one whatever the macroscopic Reynolds number and for all the thermal steps (Figure 11a). The saturation of the Darcian contribution (Figure 11b) is reached for even lower Reynolds number (1700 to 1000) when increasing the temperature (from $300 \mathrm{~K}$ to $750 \mathrm{~K}$ roughly). But for a given Reynolds number, the Forchheimer's contribution is more important for high temperature condition (Figure 11a). This can be linked to fluid properties or to the porous sample thermal expansion. For all the hot tests on metallic samples, some impurities are found by SEM and EDS analysis inside the porous media after the tests due to seal damage. No significant mass loss is observed for the samples, no damage appears visually on their surface.

\section{Figure 11 should be placed here}

The sample SS5 presents quite constant Darcian term up to $1150 \mathrm{~K}$ (Figure 12a) but these values are about $30 \%$ greater than the reference data range $\left(5.08 .10^{-13} \mathrm{~m}^{2}\right.$ to $\left.1.02 .10^{-12} \mathrm{~m}^{2}\right)$ because the permeation cell does not allow to test sample with permeability of the order of $10^{-12} \mathrm{~m}^{2}$. Close to this value, the accuracy is dramatically decreasing while it can be as low as few percent for permeability around $10^{-16} \mathrm{~m}^{2}$. The uncertainty on the temperature determination is lower for the class 5 test due to a lower thermal dispersion during the successive hydraulic steps. Considering the Forchheimer's term, it significantly varies from a factor 4. It increases from $8.10^{-7} \mathrm{~m}$ to $16.10^{-7} \mathrm{~m}$ before decreasing around $800 \mathrm{~K}$ down to $4.10^{-7} \mathrm{~m}$. It could also be seen as constant around $10^{-6} \mathrm{~m}$ with a large lack of accuracy. The same trend is observed for the sample SS40. It also shows on overall constant Darcian permeability with a probable increase over $500 \mathrm{~K}$ (Figure 12b). Moreover, the Forchheimer's term increases up to $500 \mathrm{~K}$ and it suddenly decreases, may be due to thermal expansion effect of porous material.

\section{Figure 12 should be placed here}

For the $\mathrm{C} / \mathrm{SiC}$ composite sample $\mathrm{SA}$, very low mass flow rates are used during the tests because of the permeability and of the high related pressure drop. As a consequence, the inlet temperature increases slightly while the outlet one remains constant in case of nitrogen flow. The cell is not cooled down by the flow but on the opposite, it is heated due to convection. Another consequence of this so small permeation is the operating pressure, which reaches about 60 bars for mass flow rate lower than $50 \mathrm{mg} . \mathrm{s}^{-1}$. The Forchheimer's term is nevertheless determined for the present composite sample despite this very low flow rate (but the uncertainties highly increase). To ensure the composite integrity, it has been decided to not test it under pressure as high as 250 bars, for which it was hoped to get turbulent regime. The Darcy's value at ambient conditions $\left(6.10^{-17} \mathrm{~m}^{2}\right)$ is found to decrease down to 4.2.10 $10^{-17} \mathrm{~m}^{2}$ around $400 \mathrm{~K}$ before stabilisation or very slight decrease trend (Figure 13). The Forchheimer's permeability is constant around $2.10^{-12} \mathrm{~m}$ (Figure 13). SEM visualisation and EDS (Energy Dispersive 
Spectroscopy) analysis have been performed and it confirms the C/SiC composition (55 wt.\% C, 44 wt.\% Si and 1 wt.\% O).

\section{Figure 13 should be placed here}

\subsection{Permeation of reactive fluid under high temperature conditions}

The pyrolysis test is conducted under stationary thermal conditions (ambient and $750 \mathrm{~K}$ ) with liquid n-dodecane (VWR, Rectapur), for a given mass flow rate (from $0.035 \mathrm{~g} . \mathrm{s}^{-1}$ to $0.16 \mathrm{~g} . \mathrm{s}^{-1}$ ). The permeation cell outlet absolute pressure is regulated at 60 bars and the inlet pressure is measured. A class 3 SS sample is studied. The pressure losses have been measured before starting the reactor heating for different mass flow rates with liquid n-dodecane. A Darcy's term of $1.934 .10^{-13} \mathrm{~m}^{2}$ is determined (the dodecane liquid properties are those from the NIST). This is in the constructor's range $\left(1.30 .10^{-13} \mathrm{~m}^{2}\right.$ and $\left.2.54 .10^{-13} \mathrm{~m}^{2}\right)$. No Forchheimer's term can be estimated due to the low mass flow rate.

The furnace temperature is then increased to get a fluid temperature in the cell close to $750 \mathrm{~K}$ (Figure 14). The fluid gets supercritical. Then, pyrolysis occurs when reaching this temperature $-2700 \mathrm{~s}$ of experimental time- as seen on the outlet FTIR signal (Figure 14). Liquid samples have been collected and analysed by GC/MS (Table 2). A pyrolysis rate around $17 \mathrm{vol} . \%$ is found. The class 3 Poral sample is found to be highly jammed up by black deposit on the cross section exposed to through flow (Figure 15a). A weight of $158.1 \mathrm{mg}$ is found, which gives a coking rate of $21.85 \mu \mathrm{g} \cdot \mathrm{cm}^{-2} \cdot \mathrm{s}^{-1}$, which is in qualitative good agreement with previous work on open tubular SS reactor (Gascoin 2008b). A maximum value of about $20 \mu \mathrm{g} \cdot \mathrm{cm}^{-2} . \mathrm{s}^{-1}$ was found for residence time around $200 \mathrm{~s}$ with SS reactor. This shows that the hydraulics (Darcy's or turbulent and laminar flows with Reynolds number from 1 to $10^{5}$ ) has a minor impact of coke formation compared to the residence time and to the thermal effects notably. The SEM visualisation (Figure 15b) clearly shows the uniform presence at the surface of coke deposit under carbon spherical shape as was described in earlier work (Gascoin 2010). This shows the difficulty to study very low permeability media due to the rapidity of porosity modification by the flow and chemical phenomena. After cleaning and new SEM observations (Figure 15c), the coke deposit is found in the deepness of the sample where the coke spherical particles are much smaller than the metallic sample particles.

\section{Figure 14 should be placed here \\ Figure 15 should be placed here \\ Table 2 should be placed here}

The hydraulic data of this test have been exploited to determine the Darcy's term at $750 \mathrm{~K}$ of sample's temperature. A value between $2.22 .10^{-13} \mathrm{~m}^{2}$ and $6.67 .10^{-13} \mathrm{~m}^{2}$ is found (large uncertainty). This is in good agreement with preceding hot results (Figure 10a). The permeability after clogging has been determined later under ambient temperature with inert fluid. A Darcian value of $4.06 .10^{-14} \mathrm{~m}^{2}$ is found. This clearly shows the blockage effect of the coke because the former values were $K_{D}=2.32 .10^{-13} \mathrm{~m}^{2}$ at ambient conditions (section 3.3). All the permeability values are summarized in Table 3.

\section{Table 3 should be placed here}

\section{Conclusion}

For high speed flight applications, the cooling of porous structures has to be investigated to understand the related coupled phenomenon such as heat and mass transfer, fuel pyrolysis and coke formation. In the framework of the present permeation project, supported by the ESA-ESTEC, an experimental bench has been presented to conduct high temperature and pressure studies of flow through porous metallic and composite structures (for Darcian permeability of $10^{-12} \mathrm{~m}^{2}$ and lower). The maximum operating condition, which was encountered in this study, is $1150 \mathrm{~K}, 60$ bars and $0.5 \mathrm{~g} . \mathrm{s}^{-1}$. This is far beyond the conditions which are generally observed in open literature. The temperature, pressure, mass flow rate and chemical compositions are monitored on each side of the porous media and also inside in case of liquid hydrocarbon fuel test.

Thanks to these tests, the Darcy's and Forchheimer's terms have been estimated by plotting the pressure losses as a function of the mass flow rate. This has been done for a large number of metallic and composite samples. The pore Reynolds number has been estimated for metallic samples and the theoretical limit between Darcian and non Darcian flow is found around unity. Over hundred permeation tests have been carried out to test several gas natures, two fluid phases and multi-species flow, to consider different test conditions under stationary and transient conditions and to verify the reproducibility. The results obtained with inert fluid then with reactive one have been compared to estimate the blockage effect of the coking activity. The coke formation has been monitored during the 
tests by successive mass balance and the coking rate is found in very good agreement with former results (Gascoin 2008b). This study enables to investigate fuel pyrolysis in porous medium. The effect of the residence time, much higher with porous sample than without, is demonstrated and the fuel permeation through a porous structure highly favors the chemical reaction. A pyrolysis rate of $17 \%$ is found while none was previously found for tubular open reactor in the same thermal and pressure conditions under $850 \mathrm{~K}$ (Gascoin 2010).

To the author's knowledge, this study is the first to present permeation data in the following cases: multiphase and multispecies reacting flow, coke formation, conditions up to $1150 \mathrm{~K}$ and 60 bars, for metallic and composite samples. The catalytic effect will now be investigated by reproducing several pyrolysis tests with several material nature (red brass, stainless steal, composite) in similar permeability conditions. Other analytical method will be applied on available permeation results, particularly at high temperature to improve the permeability determination method. Other composite samples will be tested, benchmark will be performed and reactive tests will be pursued under supercritical and biphasic conditions with numerical modeling effort. Several permeabilities determination methods will be compared in a near future.

\section{Acknowledgments}

This work was supported by the ESA-ESTEC, Contract no.: 3-12861/09/NL/PA. The author would like to sincerely thank J. Steelant from ESA, G. Fau, P. Gillard and J. Bioud from PRISME and M. Bouchez, B. Le Naour and J. Bertrand from MBDA-France for their help involving this project. The highly valuable work of D. Blanc and D. Courilleau involving the measurement cell has been greatly appreciated.

\section{References}

Abraham G.,2009, "Etude et développement d'une méthode d'analyse par spectroscopie infrarouge appliquée à la pyrolyse d'hydrocarbures en conditions supercritiques et transitoires", Ph.D. Thesis, 04/12/2009, University of Orléans, France

Alkam M. K. and Al-Nimr M. A., 1998, "Transient non-Darcian forced convection flow in a pipe partially filled with a porous material", Int. J. Heat Mass Transfer. Vol. 41, No. 2, pp. 347-356

Aulisa E., et al., 2009, "Geometric framework for modeling nonlinear flows in porous media, and its applications in engineering", Nonlinear Analysis: Real World Applications (2009), doi:10.1016/j.nonrwa.2009.03.028

Bouchez M, Falempin F, Cahuzac G, Avrashkov V, 2002, "PTAH-SOCAR Fuel-Cooled Composite Materials Structure", 11th AIAA/AAAF International Space Planes and Hypersonic Systems and Technologies Conference 29 September - 4 October 2002 / Orleans, France AIAA 2002-5135

Bouchez M., et al. 2008, "Material-Aero-Thermal Interaction Computations in the ATLLAS European Programme", AIAA-2008-4670, 44th AIAA/ASME/SAE/ASEE Joint Propulsion Conference and Exhibit, Hartford, CT, July 20th-23rd, 2008

Choi M.A, Leeb M.H., Chang J., Jong Leed S., 1998, "Permeability modeling of fibrous media in composite processing", J. Non-Newtonian Fluid Mech. 79, pp. 585-598, 1998.

DHAOUADI H., 2010, "Séparation solide-fluide", UHP Nancy 1, http://www.cyber.uhp-nancy.fr/demos/CHSSF/cha_2/fluides_comp.html, last access 08/07/2010

Eudier M., "Propriétés et applications des matériaux frittés", Techniques de l'Ingénieur, M866

Federico S., Herzog W., 2008, "On the permeability of fibre-reinforced porous materials", International Journal of Solids and Structures 45, pp. 2160-2172, 2008.

Gascoin N., et al.,2008a, "Pyrolysis of Supercritical Endothermic Fuel: Evaluation for Active Cooling Instrumentation.", International Journal of Chemical Reactor Engineering, Vol. 6, Article A7, Ed. The Berkeley Electronic Press, 2008

Gascoin N., Gillard P., Bernard S., Bouchez M., 2008b, "Characterisation of coking activity during supercritical hydrocarbon pyrolysis", Fuel Processing and Technology, Vol. 89, Issue 12, December 2008, pp14161428.

Gascoin N., 2010, "Etude et mesure de paramètres pertinents dans un écoulement réactif application au refroidissement par endo-carburant d'un super-statoréacteur", Editions Universitaires Européennes, avril 2010, ISBN13: 978-6131501074, 376 pages.

Hadim A., 1994, "Numerical Study of Non-Darcy Mixed Convection in a Vertical Porous Channel", Journal of thermophysics and heat transfer, Vol. 8, No. 2, pp 371-373

Hansbo P., Juntunen M., 2009, "Weakly imposed Dirichlet boundary conditions for the Brinkman model of porous media flow", Applied Numerical Mathematics 59 (2009) 1274-1289 
Kim M.-Y., Park E.-J., 1999, "Fully Discrete Mixed Finite Element Approximations for Non-Darcy Flows in Porous Media", Computers and Mathematics with Applications 38 (1999) 113-129

Kladias N. and Prasad V., "Experimental Verification of Darcy-Brinkman-Forchheimer Flow Model for Natural Convection in Porous Media", J. Thermophysics, VOL. 5, NO. 4, pp560

Klimenko A.Y., Abdel-Jawad M.M., 2007, "Conditional methods for continuum reacting flows in porous media", Proceedings of the Combustion Institute 31 (2007) 2107-2115

Krishna D. J., Basak T., Das S. K., 2008, "Natural convection in a heat generating hydrodynamically and thermally anisotropic non-Darcy porous medium", International Journal of Heat and Mass Transfer 51 (2008) 4691-4703

Langener T., von Wolfersdorf J., Laux T., Steelant J.,2008, "Experimental Investigation of Transpiration Cooling with Subsonic and Supersonic Flows at Moderate Temperature Levels", 44th AIAA/ASME/SAE/ASEE Joint Propulsion Conference \& Exhibit 21 - 23 July 2008, Hartford, CT, AIAA 2008-5174

Martin A. and Boyd I. D., 2008, "Simulation of pyrolysis gas within a thermal protection system", 40th Thermophysics Conference 23 - 26 June 2008, Seattle, Washington, AIAA 2008-3805

Moutsopoulos K.N., 2009, "Exact and approximate analytical solutions for unsteady fully developed turbulent flow in porous media and fractures for time dependent boundary conditions", Journal of Hydrology 369, 78-89

Murthy P.V S.N. and Singh P., 2000, "Thermal Dispersion Effects on Non-Darcy Convection over a Cone", Computers and Mathematics with Applications 40 (2000) 1433-1444

Nguyen Q P., Currie P K., Marten Buijse, Pacelli L.J. Zitha,2007, "Mapping of foam mobility in porous media", Journal of Petroleum Science and Engineering 58 (2007) 119-132

Park O.Y., Lawrence TW., 2003, "High Temperature Permeability of Carbon Cloth Phenolic Composite", 39th AIAA/ASME/SAE/ASEE Joint Propulsion Conference and Exhibit 20-23 July 2003, Huntsville, Alabama, AIAA 2003-5242

Pazos F.A., Bhaya A., Martins Compan A.L., 2009, "Calculation of Klinkenberg permeability, slip factor and turbulence factor of core plugs via nonlinear regression", Journal of Petroleum Science and Engineering 67 159167

Peddiraju P., Grenoble R., Fried K., Gates T., Lagoudas D.C., 2005, “Analytical Predictions and Experimental Measurements of Hydrogen Permeability in a Microcrack Damaged Composite", 46th AIAA/ASME/ASCE/AHS/ASC Structures, Structural Dynamics \& Materials Conference, 18-21 April 2005, Austin, Texas, AIAA 2005-2087

Polehn R. A., Keyhani M., and Parang M., "Transient Compressible Flow in Variable Permeability Media", $J$. Thermophysics, Vol. 8, No. 2: Technical Notes

Poling B.E., Prausnitz J.M., O'Connell S.P., "The properties of Gases and Liquids", Fifth Edition, International Edition, Mac Graw Hill

Rajagopal K.R., et al., 2009, "A systematic approximation for the equations governing convection-diffusion in a porous medium", Nonlinear Analysis: Real World Applications (2009), doi:10.1016/j.nonrwa.2009.07.010

Rathish B.V., Shalini K, 2003, "Free convection in a non-Darcian wavy porous enclosure", International Journal of Engineering Science 41 (2003) 1827-1848

Riccius J.R., Greuel D., Haidn O. J., Leicht T., 2005, "Coupled CFD Analysis of the Hot Gas and the Coolant Flow in Effusion Cooled Combustion Chambers", 41st AIAA/ASME/SAE/ASEE Joint Propulsion Conference \& Exhibit 10-13 July 2005, Tucson, Arizona, AIAA 2005-4437.

Samper J., Zheng L., Fernández A. M., Montenegro L.,2006, "Inverse modeling of multicomponent reactive transport through single and dual porosity media", Journal of Contaminant Hydrology 98 (2008) 115-127

Seddeek M.A., "Influence of viscous dissipation and thermophoresis on Darcy-Forchheimer mixed convection in a fluid saturated porous media", Journal of Colloid and Interface Science 293 (2006) 137-142

Shields R.J., Bhattacharyya D., Fakirov S., 2008, "Oxygen permeability analysis of microfibril reinforced composites from PE_PET blends", Composites: Part A 39, pp. 940-949, 2008.

Soller S., Kirchberger C., Kuhn M., Langener T., Bouchez M., Steelant J., 2009, "Experimental Investigation of Cooling Techniques and Materials for Highspeed Flight Propulsion Systems", 16th AIAA/DLR/DGLR International Space Planes and Hypersonic Systems and Technologies Conference, October 2009, Bremen, Germany, AIAA 2009-7374

Steelant J., 2008, "ATLLAS: Aero-Thermal Loaded Material Investigations for High-Speed Vehicles", AIAA2008-2582, 15th AIAA International Space Planes and Hypersonic Systems and Technologies Conference, Dayton, OH, Apr. 28th-May 1st, 2008

Steelant J., 2009, "Achievements obtained on Aero-Thermal Loaded Materials forHigh-Speed Atmospheric Vehicles within ATLLAS", AIAA-2009-7225, 16th AIAA/DLR/DGLR International Space Planes and Hypersonic Systems and Technologies Conference, Bremen, Germany, October 19th-22nd, 2009 
Tully L. R., Omar A., Chung J. N., Carroll B. F., Tucker P. K., 2005, "Fluid Flow and Heat Transfer in a Liquid Rocket Fuel Injector", 41st AIAA/ASME/SAE/ASEE Joint Propulsion Conference \& Exhibit 10-13 July 2005, Tucson, Arizona, AIAA 2005-4127

Valdes-Parada F.J., Ochoa-Tapia J.A., Alvarez-Ramirez J., 2007, "On the effective viscosity for the DarcyBrinkman equation", Physica A 385 (2007) 69-79

Xu J. and Sanka B. V.,2007, "Parametric Investigation of Gas Permeability in Cross-Ply Laminates Using Finite Elements", AIAA Journal Vol. 45, No. 4, April 2007

Xu J., Sankar B. V., 2008, "Prediction of stitch crack evolution and gas permeability in multidirectional composite laminates", Composites: Part A 39, pp. 1625-1631, 2008.

Zhang B. and Zhao Y., 1999, "Numerical Simulations o Fluid Flow ad Convection Heat Transfer Through Fluid/Porous Layers", AIAA 1999-3627

Zhao J. Z. and Chen T. S., 2003, "Non-Darcy Effects on Nonparallel Thermal Instability of Horizontal Natural Convection Flow", Journal Of Thermophysics And Heat Transfer Vol. 17, No. 2, April-June 2003

Zhou F., Kuentzer N., Simacek P., Advani S. G., Walsh S., 2006, "Analytic characterization of the permeability of dual-scale fibrous porous media”, Composites Science and Technology 66, pp. 2795-2803, 2006 
Table 1. Properties and pore diameter of porous media obtained experimentally.

\begin{tabular}{|c|c|c|c|c|c|c|c|c|c|c|}
\hline \multirow{3}{*}{ Density $\left(\mathrm{kg} \cdot \mathrm{m}^{-3}\right)$} & \multicolumn{4}{|c|}{ Stainless Steel } & \multirow{2}{*}{\multicolumn{2}{|c|}{$\begin{array}{c}\text { Red Brass } \\
8800\end{array}$}} & \multicolumn{4}{|c|}{ Composite } \\
\hline & \multicolumn{4}{|c|}{7850} & & & \multicolumn{3}{|c|}{1600} & \multirow[t]{2}{*}{2500} \\
\hline & \multicolumn{2}{|c|}{ Class 3} & Class 5 & Class 40 & Class 3 & Class 30 & \multicolumn{3}{|c|}{$\mathrm{C} / \mathrm{SiC} \mathrm{CMC}$} & \\
\hline Thickness (mm) & 2 & 3 & 3 & 3 & 3 & 3 & 1.5 & 4.5 & 7.5 & 3 \\
\hline Fabrication & \multicolumn{6}{|c|}{ spheres based material } & \multicolumn{2}{|c|}{ weaved layers } & $\begin{array}{l}3 \text { different } \\
\text { layers linked }\end{array}$ & $\begin{array}{c}\text { homogeneous } \\
\text { material }\end{array}$ \\
\hline Overall porosity () & $28.3 \%$ & $30.4 \%$ & $34.3 \%$ & $39.7 \%$ & $40.3 \%$ & $44.0 \%$ & $8.8 \%$ & $13.3 \%$ & $30.9 \%$ & $14.6 \%$ \\
\hline Open porosity () & \multicolumn{2}{|c|}{$9.1 \%$} & $25.1 \%$ & $47.2 \%$ & $42.0 \%$ & $33.7 \%$ & $2.6 \%$ & $6.9 \%$ & $15.9 \%$ & - \\
\hline Grain diameter $(\mu \mathrm{m})$ & 10.1 & 14.1 & 23.7 & 97.3 & 9.2 & 119.4 & 1.56 & 3.3 & 0.57 & 0.56 \\
\hline $\begin{array}{l}\text { Computed pore } \\
\text { diameter }(\mu \mathrm{m})\end{array}$ & 2.9 & 4.1 & 8.2 & 42.7 & 4.2 & 62.6 & 0.09 & 0.34 & 0.17 & 0.06 \\
\hline Porous sample $n^{\circ}$ & ss3-2 & SS3 & SS5 & SS40 & BR3 & BR30 & $\mathrm{SC}$ & SB & sw & SA \\
\hline
\end{tabular}


Table 2. Pyrolysis products composition for fluid temperature of $750 \mathrm{~K}$, sample at the cell outlet after the test.

\begin{tabular}{ccccc}
\hline \hline $\begin{array}{c}\text { Retention } \\
\text { time (min) }\end{array}$ & Species & nanol/mL & Vol \% & $\begin{array}{c}\text { Corrected } \\
\text { Vol \% }\end{array}$ \\
\hline 1.489 & Methyl aclohol & 6054 & & \\
1.512 & butane & 21.67 & $0.24 \%$ & $\mathbf{0 . 9 3 \%}$ \\
1.732 & 2-pentene & 8.743 & $0.09 \%$ & $\mathbf{0 . 3 7 \%}$ \\
1.762 & pentane & 55.41 & $0.60 \%$ & $\mathbf{2 . 3 7 \%}$ \\
2.358 & 1-hexene & 36.04 & $0.39 \%$ & $\mathbf{1 . 5 4 \%}$ \\
2.432 & hexane & 31.9 & $0.35 \%$ & $\mathbf{1 . 3 6 \%}$ \\
3.242 & benzene & 0.755 & $0.01 \%$ & $\mathbf{0 . 0 3 \%}$ \\
3.532 & cyclohexene & 0.426 & $0.00 \%$ & $\mathbf{0 . 0 2} \%$ \\
3.687 & 1-heptene & 33.05 & $0.36 \%$ & $\mathbf{1 . 4 1 \%}$ \\
3.83 & heptane & 16.37 & $0.18 \%$ & $\mathbf{0 . 7 0 \%}$ \\
5.191 & toluene & 1.569 & $0.02 \%$ & $\mathbf{0 . 0 7 \%}$ \\
5.674 & 1-octene & 20.64 & $0.22 \%$ & $\mathbf{0 . 8 8 \%}$ \\
5.857 & octane & 24.7 & $0.27 \%$ & $\mathbf{1 . 0 6 \%}$ \\
7.46 & p-xylene & 0.385 & $0.00 \%$ & $\mathbf{0 . 0 2} \%$ \\
7.897 & 1-nonene & 19.32 & $0.21 \%$ & $\mathbf{0 . 8 3} \%$ \\
7.972 & ethylbenzene & 0.271 & $0.00 \%$ & $\mathbf{0 . 0 1 \%}$ \\
8.081 & nonane & 29.59 & $0.32 \%$ & $\mathbf{1 . 2 6 \%}$ \\
10.069 & 1-decene & 21.5 & $0.23 \%$ & $\mathbf{0 . 9 2} \%$ \\
12.125 & 1-undecene & 6.27 & $0.07 \%$ & $\mathbf{0 . 2 7} \%$ \\
12.287 & undecane & 32.54 & $0.35 \%$ & $\mathbf{1 . 3 9 \%}$ \\
14.052 & 1-dodecene & 5.561 & $0.06 \%$ & $\mathbf{0 . 2 4 \%}$ \\
14.25 & dodecane & 8804 & $95.61 \%$ & $\mathbf{8 2 . 7 5 \%}$ \\
15.988 & tridecane & 4.745 & $0.05 \%$ & $\mathbf{0 . 2 0} \%$ \\
15.989 & 1-tridecene & 1.911 & $0.02 \%$ & $\mathbf{0 . 0 8 \%}$ \\
17.547 & 5-Tetradecene & 1.125 & $0.01 \%$ & $\mathbf{0 . 0 5 \%}$ \\
17.673 & tetradecane & 4.094 & $0.04 \%$ & $\mathbf{0 . 1 7 \%}$ \\
\hline \hline
\end{tabular}


Table 3. Permeability values determined as a function of sample and fluid nature and of sample temperature.

\begin{tabular}{|c|c|c|c|c|}
\hline & $\begin{array}{l}\text { Fluid } \\
\text { nature }\end{array}$ & $\begin{array}{c}\text { Sample } \\
\text { temperature }(\mathrm{K})\end{array}$ & $\begin{array}{l}\text { Darcy's term } \\
\left(\mathrm{m}^{2}\right)\end{array}$ & $\begin{array}{c}\text { Forchheimer's } \\
\text { term }(\mathrm{m})\end{array}$ \\
\hline SS3-2 & $\mathrm{N}_{2}$ & 298 & $1.22 \mathrm{E}-13$ & $1.47 \mathrm{E}-07$ \\
\hline \multirow{11}{*}{ SS3 } & $\mathrm{N}_{2}$ & 298 & $1.97 \mathrm{E}-13$ & $3.52 \mathrm{E}-07$ \\
\hline & $\mathrm{N}_{2}$ & 289 & $2.58 \mathrm{E}-13$ & 3.03E-07 \\
\hline & $\mathrm{N}_{2}$ & 338 & $2.52 \mathrm{E}-13$ & $3.02 \mathrm{E}-07$ \\
\hline & $\mathrm{N}_{2}$ & 402 & $2.52 \mathrm{E}-13$ & $2.59 \mathrm{E}-07$ \\
\hline & $\mathrm{N}_{2}$ & 453 & $2.50 \mathrm{E}-13$ & $2.54 \mathrm{E}-07$ \\
\hline & $\mathrm{N}_{2}$ & 516 & $2.51 \mathrm{E}-13$ & $2.53 \mathrm{E}-07$ \\
\hline & $\mathrm{N}_{2}$ & 593 & $2.61 \mathrm{E}-13$ & $1.73 \mathrm{E}-07$ \\
\hline & $\mathrm{N}_{2}$ & 668 & $2.68 \mathrm{E}-13$ & 2.77E-07 \\
\hline & $\mathrm{N}_{2}$ & 751 & $3.08 \mathrm{E}-13$ & $1.91 \mathrm{E}-07$ \\
\hline & $\mathrm{nC}_{12} \mathrm{H}_{26}$ & $300 \mathrm{~K}-750 \mathrm{~K}$ & $\begin{array}{l}2.22 \mathrm{E}-13 \\
6.67 \mathrm{E}-13\end{array}$ & - \\
\hline & $\mathrm{nC}_{12} \mathrm{H}_{26}$ & After coking & $4.06 \mathrm{E}-14$ & - \\
\hline \multirow{9}{*}{ SS5 } & $\mathrm{N}_{2}$ & 298 & $1.02 \mathrm{E}-12$ & $8.97 \mathrm{E}-07$ \\
\hline & $\mathrm{N}_{2}$ & 292.15 & $1.47 \mathrm{E}-12$ & $8.29 \mathrm{E}-07$ \\
\hline & $\mathrm{N}_{2}$ & 552.582 & $1.61 \mathrm{E}-12$ & $7.59 \mathrm{E}-07$ \\
\hline & $\mathrm{N}_{2}$ & 659.812 & $1.52 \mathrm{E}-12$ & $1.05 \mathrm{E}-06$ \\
\hline & $\mathrm{N}_{2}$ & 747.186 & $1.55 \mathrm{E}-12$ & $1.04 \mathrm{E}-06$ \\
\hline & $\mathrm{N}_{2}$ & 852.179 & $1.49 \mathrm{E}-12$ & $1.59 \mathrm{E}-06$ \\
\hline & $\mathrm{N}_{2}$ & 949.15 & $1.28 \mathrm{E}-12$ & $3.86 \mathrm{E}-07$ \\
\hline & $\mathrm{N}_{2}$ & 1049.15 & $1.36 \mathrm{E}-12$ & $7.23 \mathrm{E}-07$ \\
\hline & $\mathrm{N}_{2}$. & 1146.15 & $1.37 \mathrm{E}-12$ & 4.49E-07 \\
\hline \multirow{9}{*}{ SS40 } & $\mathrm{N}_{2}$ & 298 & $1.55 \mathrm{E}-11$ & $2.88 \mathrm{E}-06$ \\
\hline & $\mathrm{N}_{2}$ & 294 & $1.07 \mathrm{E}-11$ & 3.78E-06 \\
\hline & $\mathrm{N}_{2}$ & 346 & $1.88 \mathrm{E}-11$ & $2.36 \mathrm{E}-06$ \\
\hline & $\mathrm{N}_{2}$ & 400 & $1.00 \mathrm{E}-11$ & 4.44E-06 \\
\hline & $\mathrm{N}_{2}$ & 455 & $9.19 \mathrm{E}-12$ & $1.63 \mathrm{E}-05$ \\
\hline & $\mathrm{N}_{2}$ & 520 & $1.63 \mathrm{E}-11$ & $1.70 \mathrm{E}-04$ \\
\hline & $\mathrm{N}_{2}$ & 590 & $6.72 \mathrm{E}-11$ & 2.62E-06 \\
\hline & $\mathrm{N}_{2}$ & 640 & $2.15 \mathrm{E}-11$ & $5.88 \mathrm{E}-06$ \\
\hline & $\mathrm{N}_{2}$ & 710 & 1.23E-06 & $2.35 \mathrm{E}-11$ \\
\hline BR3 & $\mathrm{N}_{2}$ & 298 & $1.83 \mathrm{E}-12$ & $4.70 \mathrm{E}-07$ \\
\hline BR30 & $\mathrm{N}_{2}$ & 298 & $5.56 \mathrm{E}-12$ & $2.33 \mathrm{E}-06$ \\
\hline SC & $\mathrm{N}_{2}$ & 298 & $1.25 \mathrm{E}-16$ & $1.00 \mathrm{E}-18$ \\
\hline SC & $\mathrm{N}_{2}$ & 298 & $4.03 \mathrm{E}-17$ & $1.00 \mathrm{E}-18$ \\
\hline SB & $\mathrm{N}_{2}$ & 298 & $1.71 \mathrm{E}-15$ & $4.56 \mathrm{E}-10$ \\
\hline SW & $\mathrm{N}_{2}$ & 298 & $3.04 \mathrm{E}-16$ & $3.10 \mathrm{E}-10$ \\
\hline \multirow{6}{*}{ SA } & $\mathrm{N}_{2}$ & 298 & $6.07 \mathrm{E}-17$ & $2.55 \mathrm{E}-12$ \\
\hline & $\mathrm{N}_{2}$ & 292 & $6.07 \mathrm{E}-17$ & $2.55 \mathrm{E}-12$ \\
\hline & $\mathrm{N}_{2}$ & 366 & $4.34 \mathrm{E}-17$ & $1.96 \mathrm{E}-12$ \\
\hline & $\mathrm{N}_{2}$ & 466 & $4.27 \mathrm{E}-17$ & $2.03 \mathrm{E}-12$ \\
\hline & $\mathrm{N}_{2}$ & 565 & $4.13 \mathrm{E}-17$ & $2.15 \mathrm{E}-12$ \\
\hline & $\mathrm{N}_{2}$ & 660 & $4.03 \mathrm{E}-17$ & $1.98 \mathrm{E}-12$ \\
\hline
\end{tabular}




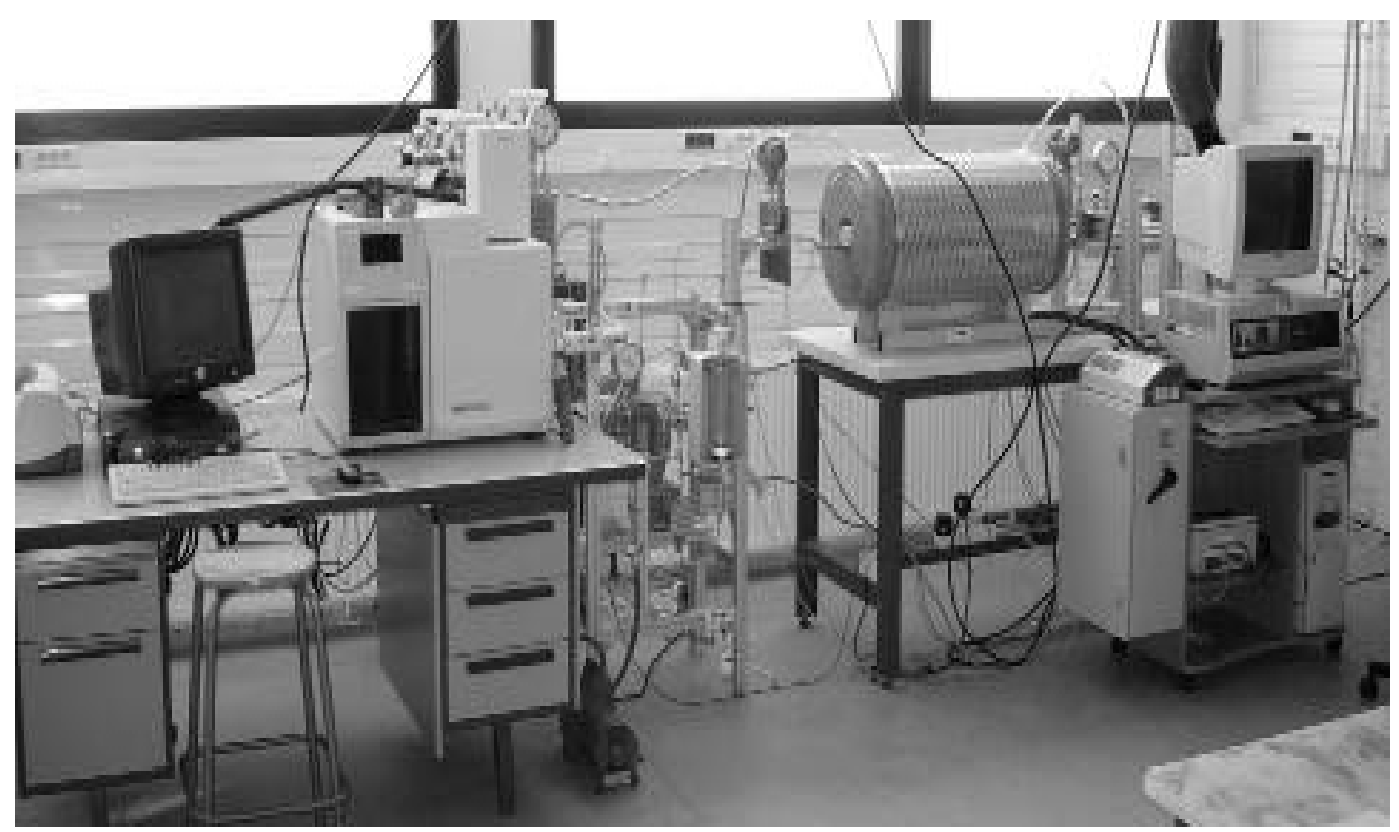

Figure 1. View of the COMPARER test bench at the PRISME laboratory in Bourges. 

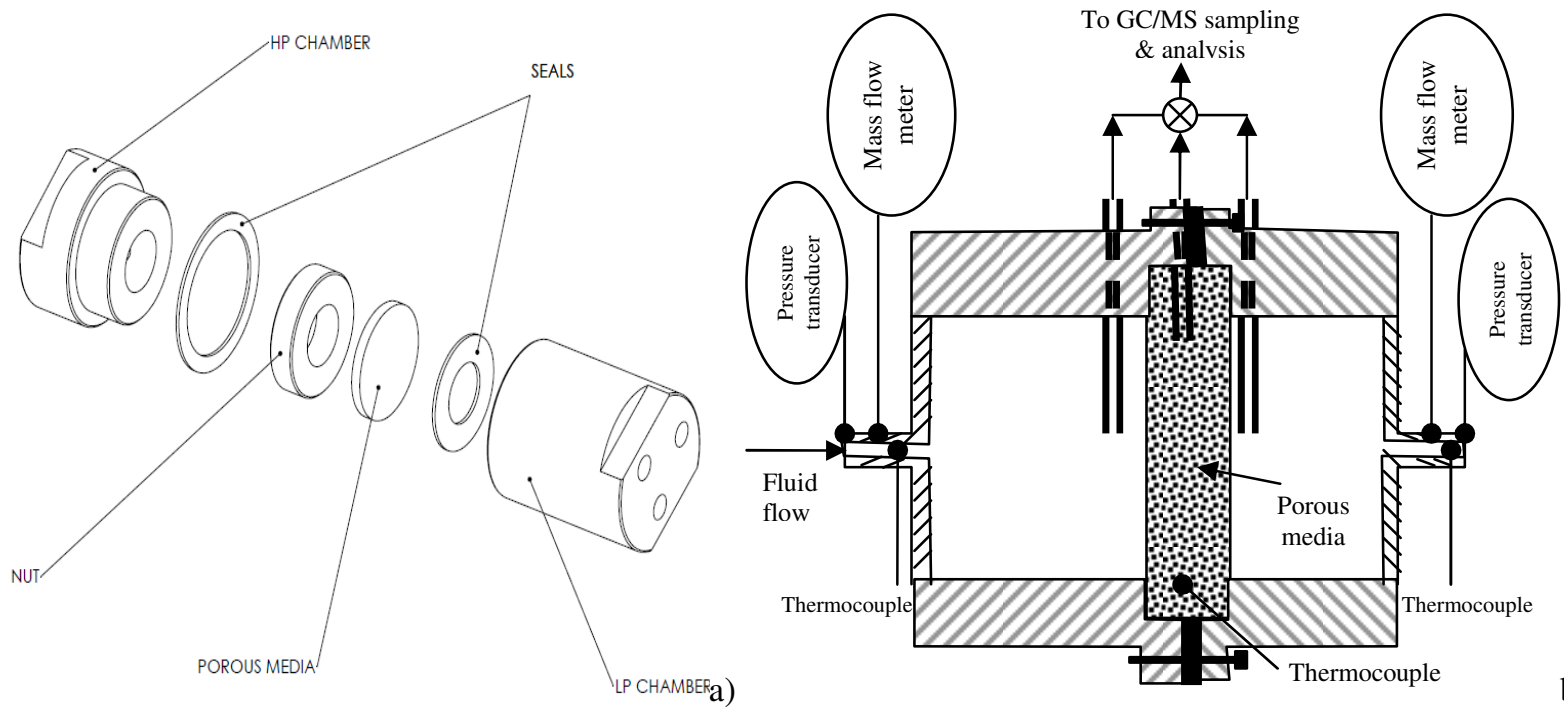

b)

Figure 2. Mounting of the sample in the cell (a) and schematic of the permeation cell with sensors (b). 


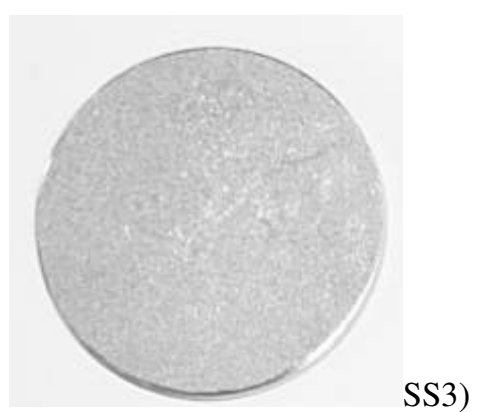

SS3)

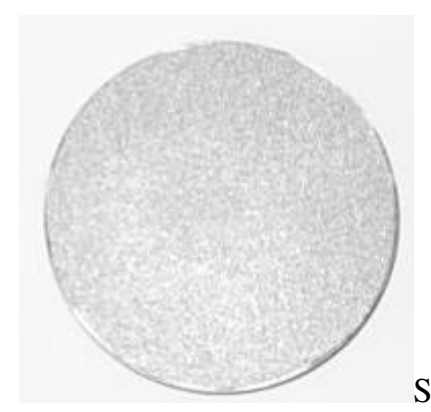

SS5)
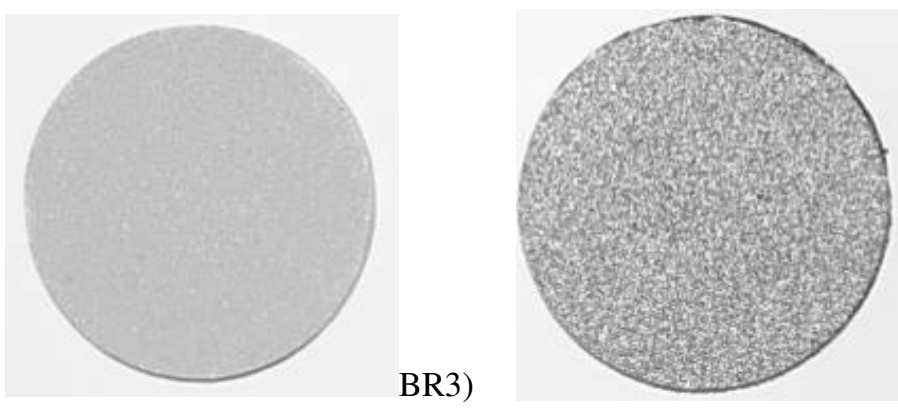

BR30)
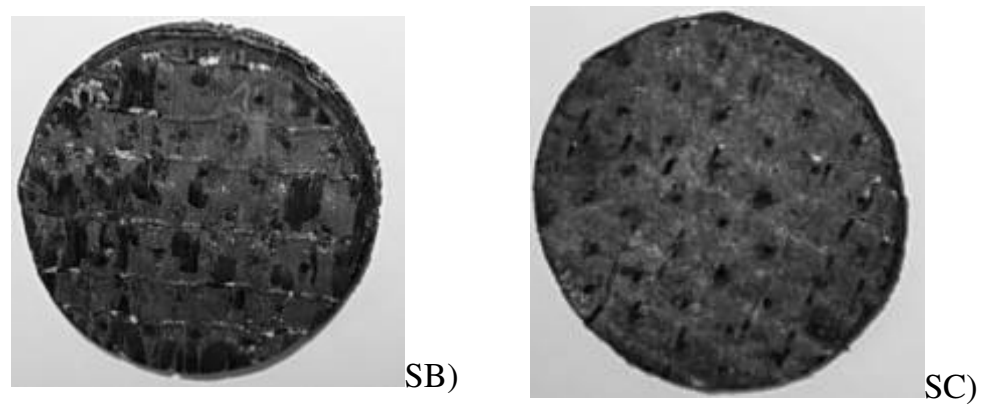

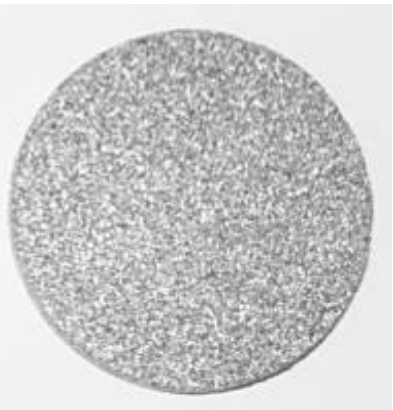

SS40)

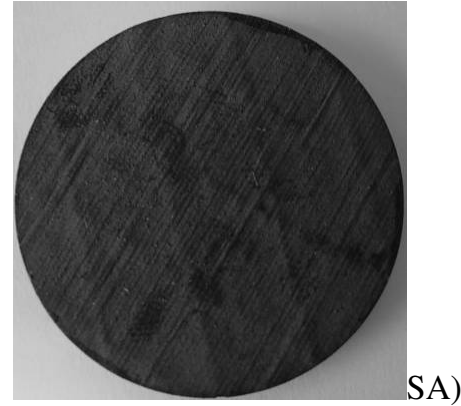

SA)

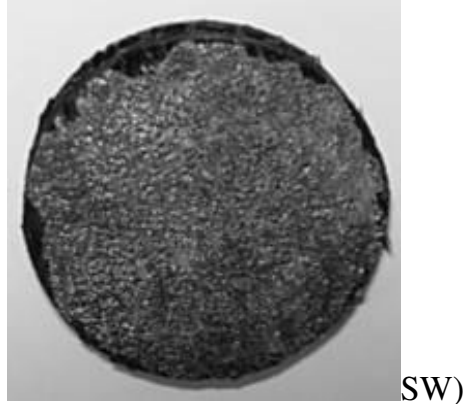

SW)

Figure 3. Pictures of porous media with corresponding denomination (SS: Stainless Steel and BR: Bronze with corresponding Poral class, SA, SB, SC and SW: CMC samples). 



Figure 4. SEM observations of porous samples: SS5 (a), BR30 (b), SA (c and d). See corresponding pictures on Figure 3. 

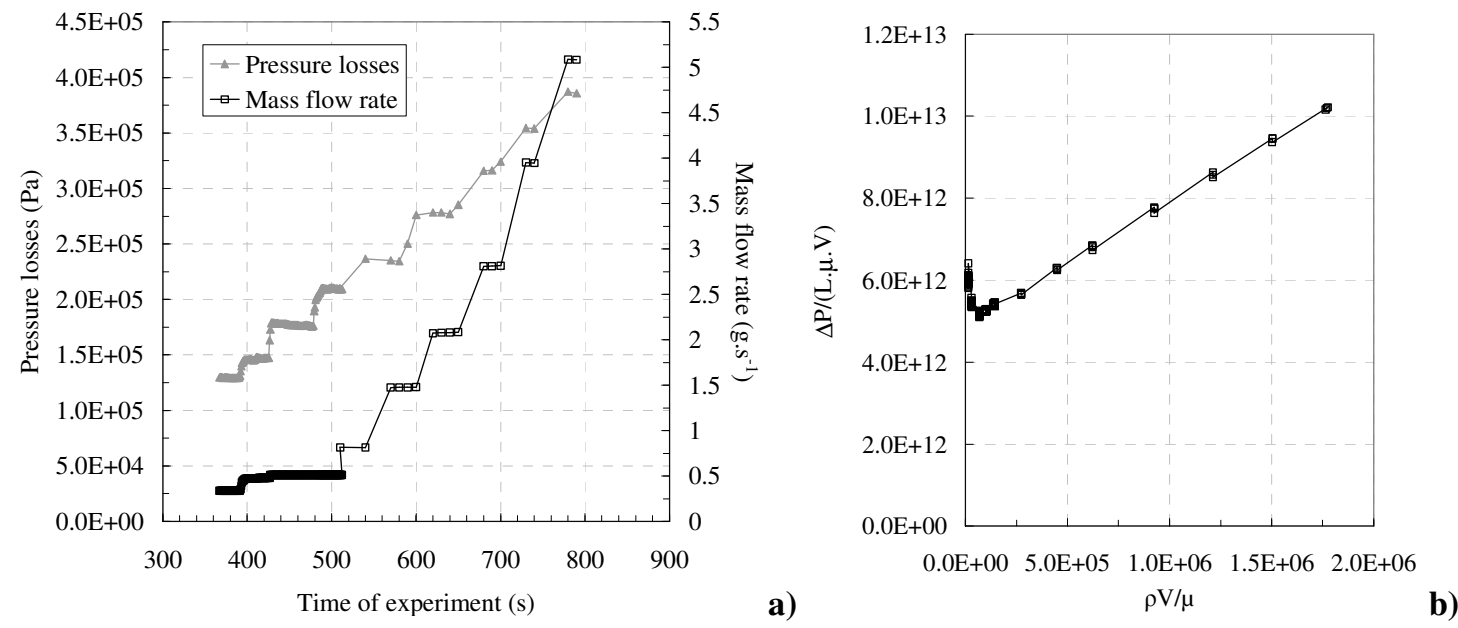

Figure 5. Pressure losses and mass flow rate (a) and determination of permeabilities (b) for a class 3 SS Poral sample of $3 \mathrm{~mm}$ thick. 


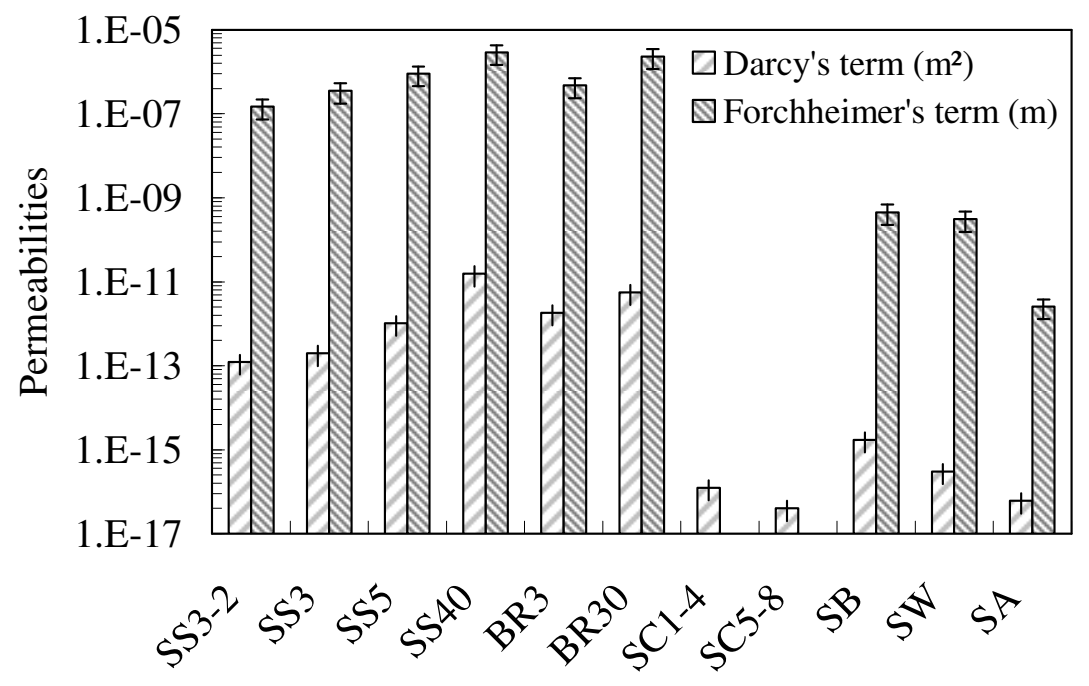

Figure 6. Permeability of porous media obtained experimentally. 


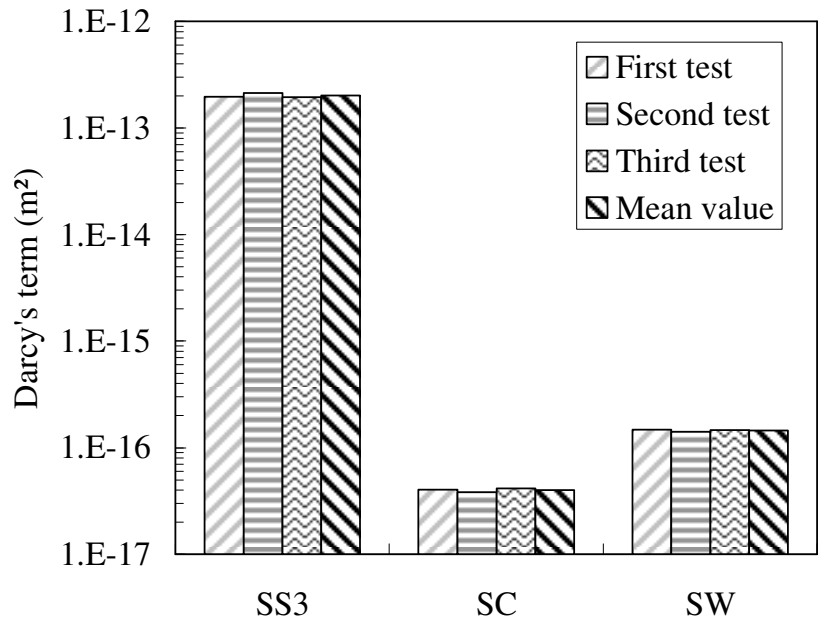

Figure 7. Reproducibility of permeation tests quantified on Darcy's term $\left(\mathrm{m}^{2}\right)$. 

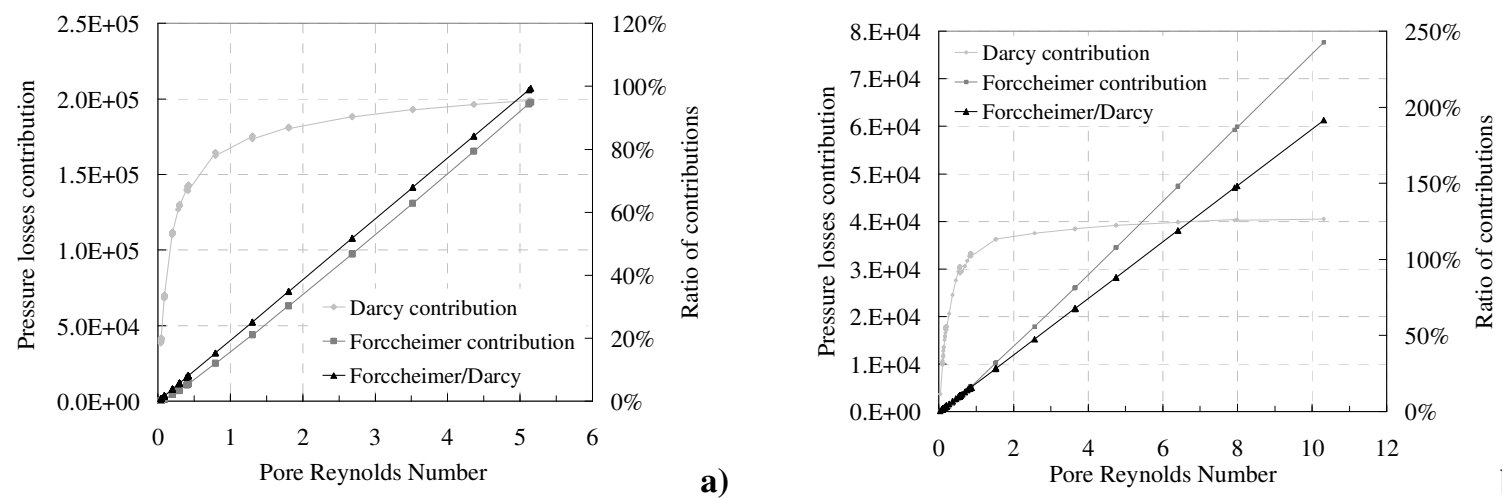

b)
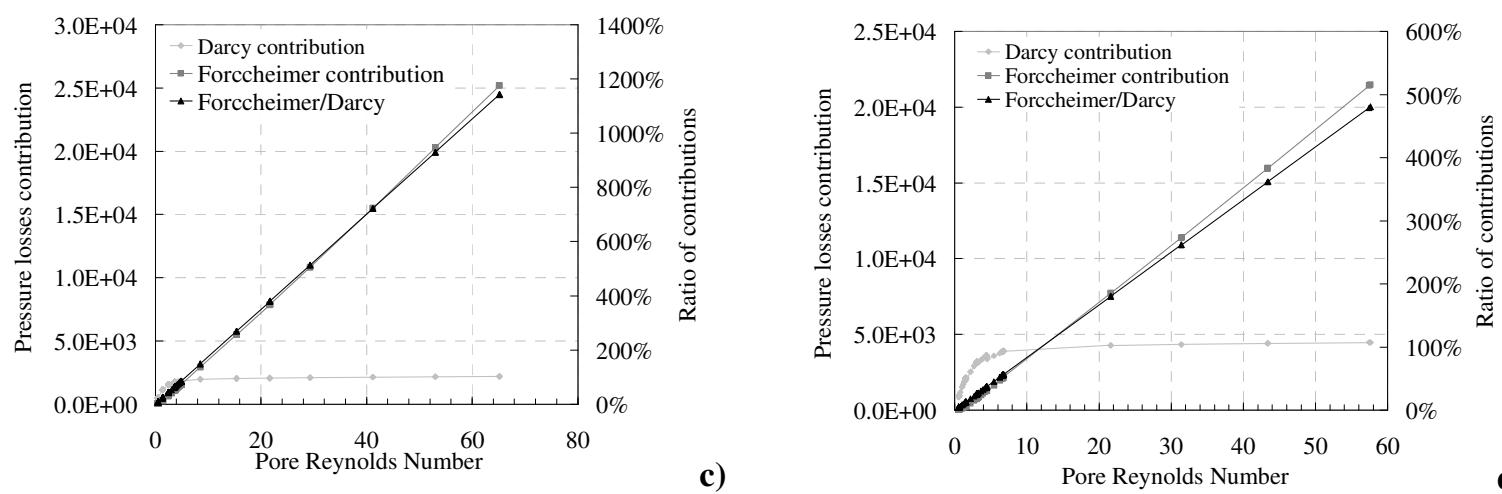

d)

Figure 8. Permeation data plotted as a function of the estimated pore Reynolds number: class 3 thickness 3 mm (a), class 5 (b), class 40 (c) SS316L Poral samples and red brass class 30 Poral sample (d). 


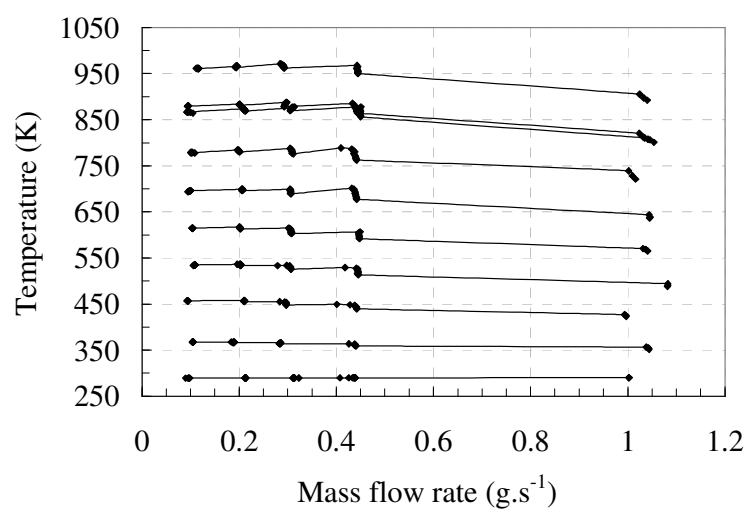

Figure 9. "Isothermal" hydraulic steps observed on sample temperature. 

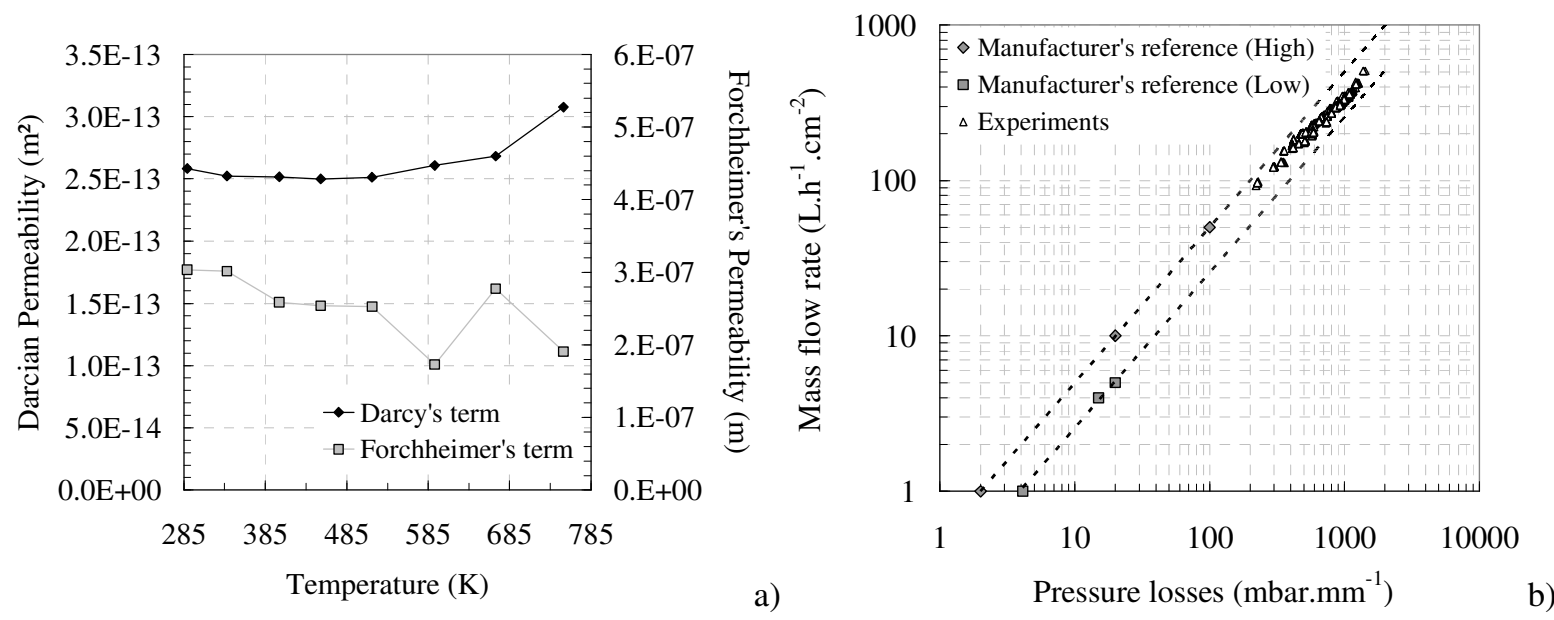

Figure 10. Darcy's and Forchheimer's value as a function of SS3 sample temperature (a) and permeation data compared to reference one (b). 

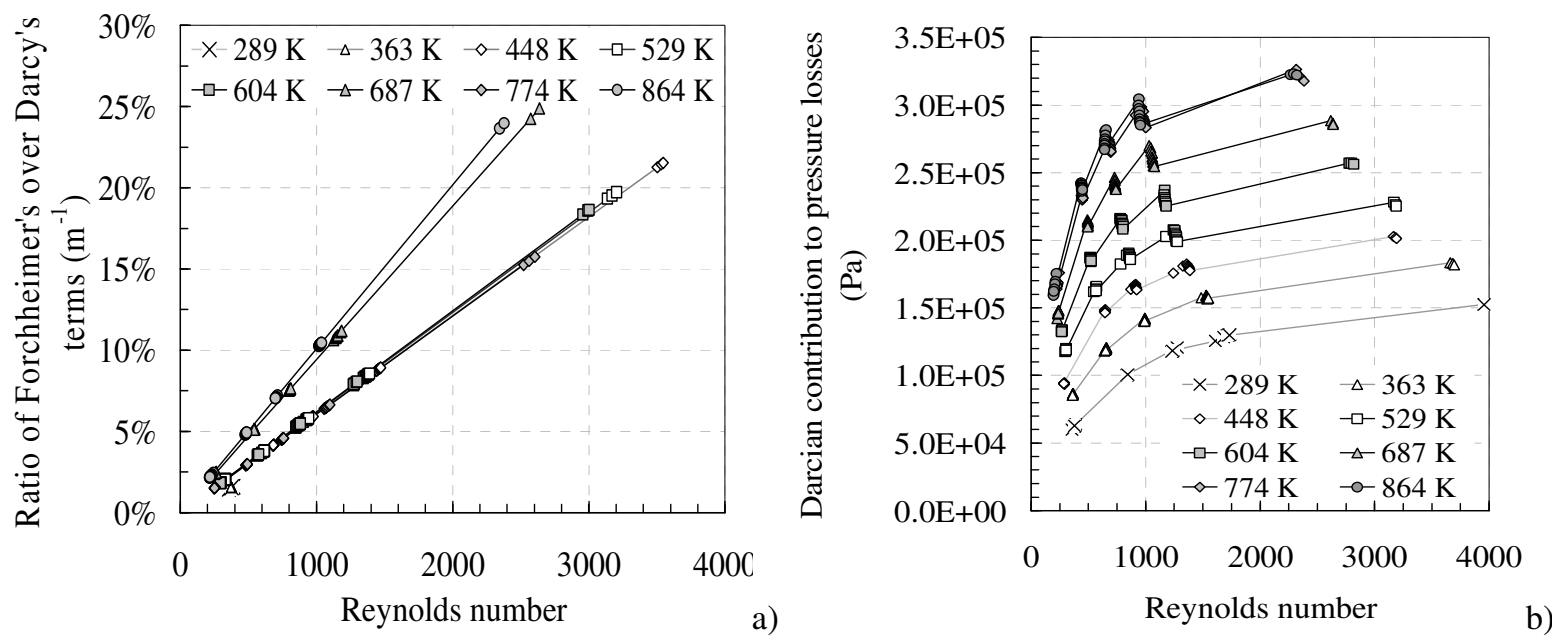

Figure 11. Ratio of the Darcian and Forchheimer's contributions (a) and Darcian pressure drop (b). 

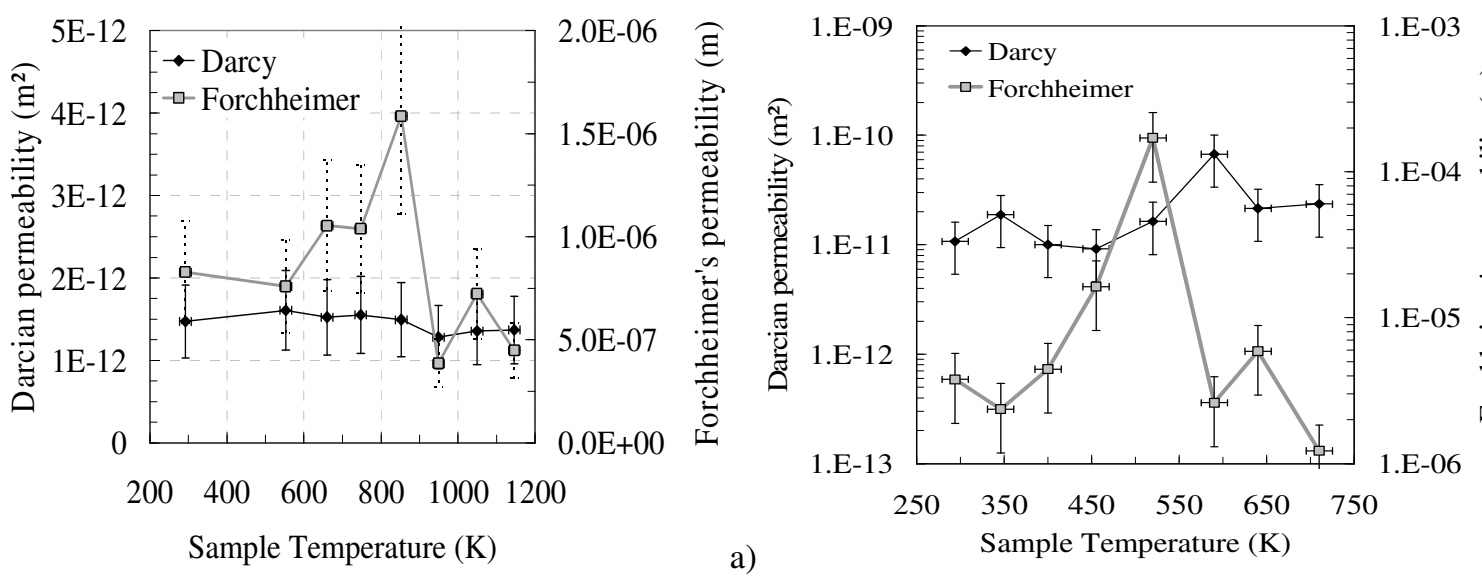

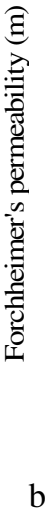

Figure 12. Darcy's and Forchheimer's terms under $\mathbf{N}_{2}$ flow for class 5 sample (a) and for class 40 sample (b). 


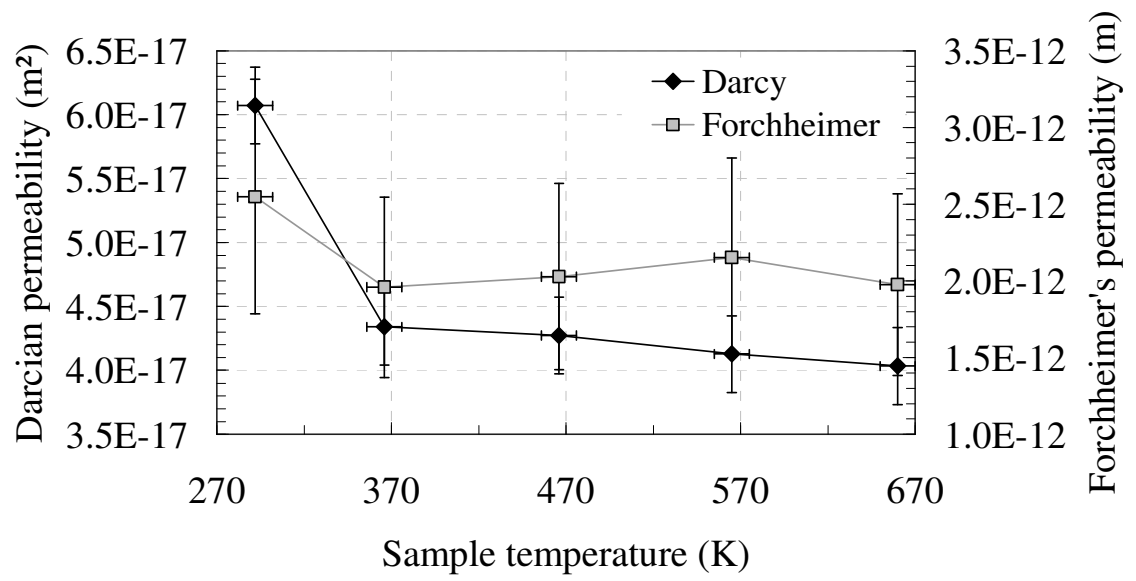

Figure 13. Determination of CMC composite sample permeabilities with $\mathrm{N}_{2}$ flow as a function of temperature. 

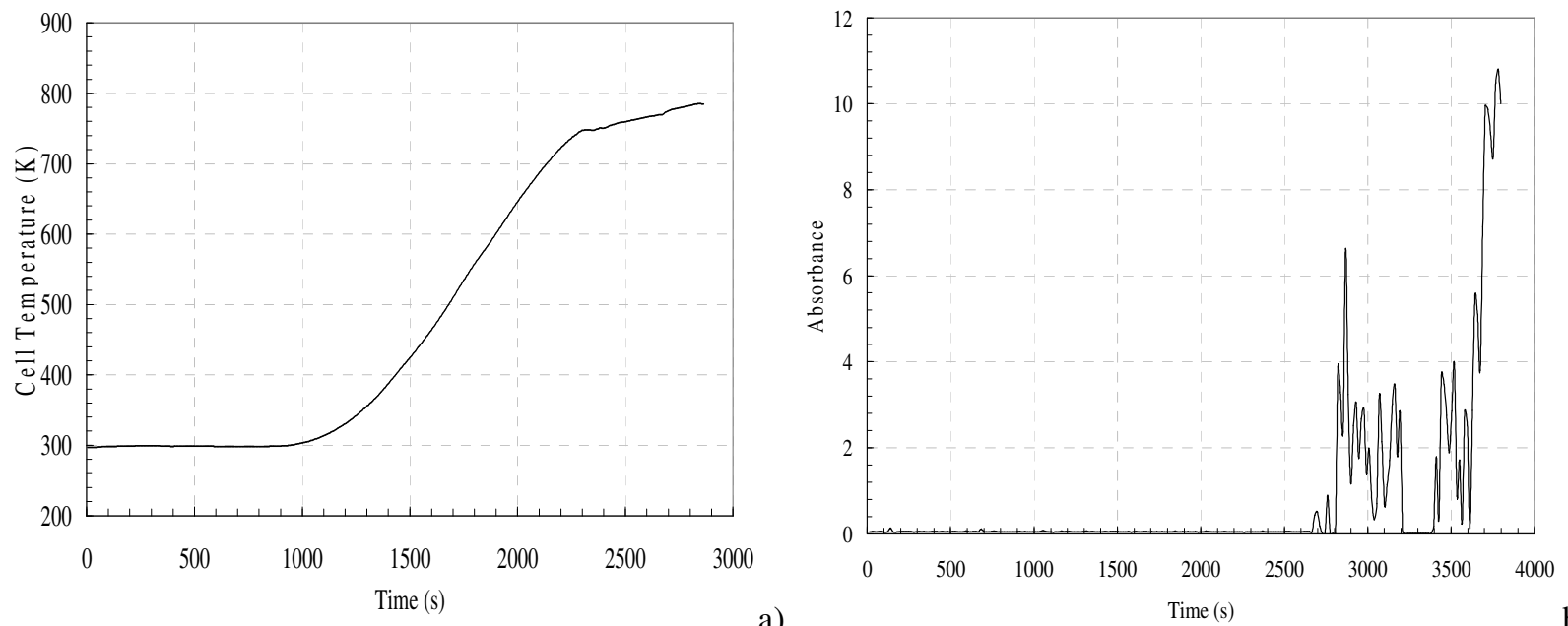

a)

b)

Figure 14. Porous sample temperature as a function of time (a) and FTIR signal (b) with pyrolysis activity over 2700 s. 

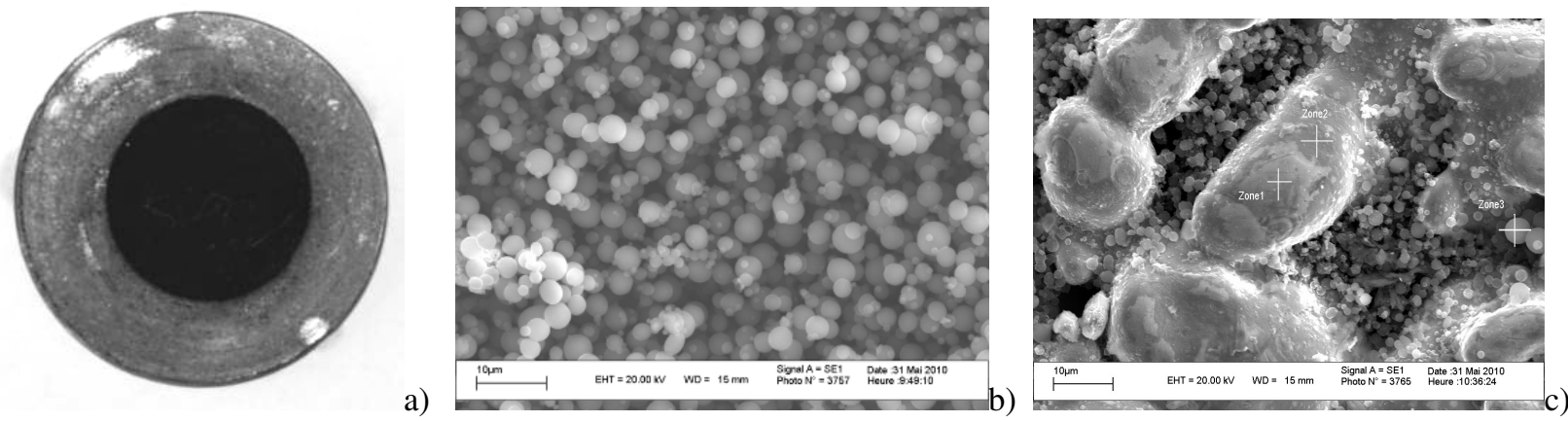

Figure 15. Class 3 SS sample after pyrolysis test (a) and associated SEM image before (b) and after surface cleaning (c). 